\title{
Low Frequency of ETV6-RUNX1 (t 12; 21) in Saudi Arabian Pediatric Acute Lymphoblastic Leukemia Patients: Association with Clinical Parameters and Early Remission
}

\author{
Khaled Aljamaan ${ }^{1}$, Talal khalid Aljumah ${ }^{1}$, Saleh Aloraibi ${ }^{2}$, Muhammad Absar ${ }^{3}$, \\ Zafar Iqbal ${ }^{4 *}$
}

\begin{abstract}
Background: Pediatric acute lymphoblastic leukemia (pALL) patients at King Abdulaziz Medical City represent a pure Saudi Arabian population. ETV6-RUNX1 positive pALL patients have good prognosis as compared to ETV6-RUNX1 negative counterparts. Therefore, frequencies of these two patient groups have a huge consideration in treatment strategies of PALL in a given population. Different geographical locations have been reported to have different frequencies of ETV6-RUNX1 ranging from 10\% in Southeast Asia to 30\% in Australia. Aim: Therefore, the objective of this study was to establish the ETV6-RUNX1 status of Saudi Arabian pALL patients and its association with clinical parameters and early remission. Materials and Methods: Clinical parameters and ETV6-RUNX1 status (using FISH technique) of pALL patients attending the Pediatric Oncology Clinic, King Abdulaziz Medical City, Riyadh from 2006 to 2011 were studied. Comparisons between ETV6-RUNX1 positive and negative groups were accomplished using chi-square test or Fisher's exact test. All statistical analyses were performed using SAS version 9.2 (SAS Institute, Inc., Cary, NC). Results: Out of 54 patients, 33 were male and 21 were females (ratio 1.57:1). B- and T-cell lineages were found in 47 (87\%) and $7(13 \%)$ patients respectively. Only $5(9.3 \%)$ patients were ETV6-RUNX1 positive while $49(80.7 \%)$ were ETV6-RUNX1 negative. All ETV6-RUNX1 patients $(100 \%)$ were of B-cell lineage and $80 \%(4 / 5)$ were in the 3-7 year age group. None of the ETV6-RUNX11 patients had $\geq 5 \%$ blasts (no remission) at day 14 as compared with 9\% in the ETV6-RUNX1 negative group (Figure 1).Conclusions: Frequency of ETV6-RUNX1 positive patients (less than 10\%) in our pALL patients is much lower than reported for most European countries, North America, Australia and Japan while it is in accordance with ETV6-RUNX1 frequencies from Egypt (11.6\%), Pakistan (10\%), Spain (2\%) and India (5-7\%). This shows ethnic differences in genetics of pALL as well as higher frequencies of ETV6-RUNX1 positive pALL mostly in more industrialized countries, probably due to some industrial pollutants or westernized lifestyle.
\end{abstract}

Keywords: Acute lymphoblastic leukemia - early remission - ETV6-RUNX1 - translocation - Saudi Arabia

Asian Pac J Cancer Prev, 16 (17), 7523-7527

\section{Introduction}

Acute Lymphoblastic Leukemia (ALL) is the cancer of lymphoid lineage of blood forming pluripotent progenitor cells in the bone marrow (Bhojwani et al., 2015).ALL is characterized by an abnormal huge number of immature lymphocytes or blasts in blood and bone marrow (Ceppi et al., 2015). It is the most common cancer in children worldwide accounting for $25 \%$ of all cancers (Pui et al., 2015). National Cancer Institute reported a sharp peak in ALL incidence among children aged 2 to 3 years $(>80$ cases per million per year), with rates decreasing to 20 cases per million for ages 8 to 10 years. The incidence of ALL among children aged 2 to 3 years is approximately fourfold greater than that for infants and is nearly tenfold greater than that for adolescents aged 16 to 21 years ( Ribera \& Oriol, 2009). In Saudi Arabia, leukemia has been reported to be third most common cancer in males (Al-Ahmadi \& Al-Zahrani, 2013) with ALL being the most common type of leukemia (Alghamdi et al., 2014; Al-Mutlaq et al., 2015). Unlike most of the western populations, Saudi Arabia has $41.7 \%$ of the population under 15 years of age, which put a large number of the population at risk of childhood cancer specifically ALL

${ }^{I}$ Division of Pediatric Hematology/Oncology Department of Oncology, ${ }^{2}$ Medical Genetics / Hematology \& Oncology, CLS, CoAMS and CoAMS, ${ }^{4}$ Medical Genetics / Clinical Laboratory Sciences, CoAMS, King Saud Bin Abdulaziz University for Health Sciences, King Abdulaziz Medical City, National Guard-Health Affairs, Riyadh, Saudi Arabia, ${ }^{3}$ Hematology, Oncology and Pharmacogenetic Engg Sciences (HOPES) Group, Department of Zoology, Faculty of Biological Sciences, University of the Punjab, Lahore, Pakistan *For correspondence:iqbalz@ksau-hs.edu.sa,drzafarmedgen@yahoo.com 
(Al-Mutlaq et al., 2015).

Many genetic abnormalities are found in Childhood ALL, which have implications in differential diagnosis/ classification, prognosis, drug selection at different phases of anti-leukemic treatment and in accessing the efficacy of the treatment (Cooper \& Brown, 2015). ETV6-RUNX1 ((t $(12 ; 21)(\mathrm{p} 13 ; \mathrm{q} 22))$ is one of the most common chromosomal abnormalities in pediatric ALL patients and is associated with favorable prognosis and prolonged survival in majority of the patients (Moorman et al., 2014). In most of the European countries, US, Japan and Australia, ETV6-RUNX1 frequency has been reported to be 20-33\% among pediatric ALL (Amor et al., 1998; Iqbal \&Tanveer 2007; Awan et al., 2012; Inaba et al., 2013; Iqbal, 2014). Nevertheless, lower frequencies of ETV6-RUNX1 have been reported in some geographical regions (Kwong \& Wong., 1997; Eguchi-Ishimae et al., 1998; Garcia-Sanz et al., 1999; Tsang et al., 2001; Rahman et al., 2006; Chung et al., 2010; Faiz \& Qazi., 2010; Mazloumi et al., 2012; Iqbal et al. 2014). This shows ethnic differences in occurrence of this prognostically important genetic lesion.

Although there are few reports about the biology and clinical outcome of childhood ALL from Saudi Arabia, reports regarding the clinical characteristics and clinical outcome of the prognostically important genetic abnormalities are lacking. Therefore, this study was carried out to find out the association of ETV6-RUNX1 positive and ETV6-RUNX1 negative pediatric ALL patients with clinical features and treatment outcome in pediatric ALL patients from King Abdulaziz Medical City, National Guard Health Affairs, Riyadh, Saudi Arabia, which are a true representation of Saudi ethnicity (Wikipedia for Saudi Arabian National Guard, 2015) and therefore best sample to show if there are ethnic differences in genetic epidemiology (e.g., ETV6-RUNX1 frequency) of Saudi pediatric ALL from other ethnic groups in the world.

\section{Materials and Methods}

\section{Patients}

This study was conducted at Division of Pediatric Hematology/Oncology Department of Oncology / King Saud Bin Abdulaziz University for Health Sciences, King Abdulaziz Medical City, National Guard Health Affairs, Riyadh, Saudi Arabia. Inclusion criteria were all

Table 1.Association of Patient Characteristics with day 14 Response in Pediatric Acute Lymphoblastic Leukemia Patients

\begin{tabular}{|c|c|c|c|c|c|}
\hline \multirow[b]{2}{*}{ Covariate } & \multirow[b]{2}{*}{ Statistics } & \multirow[b]{2}{*}{ Level } & \multicolumn{2}{|c|}{ Response Day 14} & \multirow[b]{2}{*}{ P-value* } \\
\hline & & & Poor Response $\mathrm{N}=4$ & Good Response $\mathrm{N}=45$ & \\
\hline \multirow[t]{2}{*}{ gender } & N (Row \%) & female & $1(5.26)$ & $18(94.74)$ & 0.555 \\
\hline & $\mathrm{N}($ Row \%) & male & $3(10)$ & $27(90)$ & \\
\hline \multirow[t]{3}{*}{ Age } & $\mathrm{N}($ Row \%) & $<=2$ Years & $0(0)$ & $9(100)$ & 0.471 \\
\hline & $\mathrm{N}($ Row \%) & 3 - 7 Years & $2(7.69)$ & $24(92.31)$ & \\
\hline & $\mathrm{N}($ Row \%) & $8-15$ Years & $2(14.29)$ & $12(85.71)$ & \\
\hline \multirow[t]{2}{*}{ T-cell } & $\mathrm{N}($ Row \%) & Negative & $2(4.65)$ & $41(95.35)$ & 0.016 \\
\hline & $\mathrm{N}($ Row \%) & Positive & $2(33.33)$ & $4(66.67)$ & \\
\hline \multirow[t]{2}{*}{ B-cell } & N (Row \%) & Negative & $2(33.33)$ & $4(66.67)$ & 0.016 \\
\hline & N (Row \%) & Positive & $2(4.65)$ & $41(95.35)$ & \\
\hline \multirow[t]{2}{*}{ WBC } & $\mathrm{N}($ Row \%) & $<=30000$ & $1(2.7)$ & $36(97.3)$ & 0.014 \\
\hline & $\mathrm{N}($ Row \%) & $>30000$ & $3(25)$ & $9(75)$ & \\
\hline \multirow[t]{2}{*}{ TEL-AML1 } & N (Row \%) & Negative & $4(9.09)$ & $40(90.91)$ & 0.482 \\
\hline & N (Row \%) & Positive & $0(0)$ & $5(100)$ & \\
\hline
\end{tabular}

* The p-value is calculated by chi-square test

Table 2. Association of Patient Characteristics with day 29 Response in Pediatric Acute Lymphoblastic Leukemia Patients

\begin{tabular}{|c|c|c|c|c|c|}
\hline \multirow[b]{2}{*}{ Covariate } & \multirow[b]{2}{*}{ Statistics } & \multirow[b]{2}{*}{ Level } & \multicolumn{2}{|c|}{ Response Day 14} & \multirow[b]{2}{*}{ P-value* } \\
\hline & & & Poor Response $\mathrm{N}=1$ & Good Response $\mathrm{N}=50$ & \\
\hline \multirow[t]{2}{*}{ gender } & $\mathrm{N}($ Row \%) & female & $0(0)$ & $21(100)$ & 0.398 \\
\hline & $\mathrm{N}($ Row \%) & male & $1(3.33)$ & $29(96.67)$ & \\
\hline \multirow[t]{3}{*}{ Age } & $\mathrm{N}($ Row \%) & $<=2$ Years & $0(0)$ & $9(100)$ & 0.328 \\
\hline & $\mathrm{N}($ Row \%) & 3 - 7 Years & $0(0)$ & $26(100)$ & \\
\hline & $\mathrm{N}($ Row \%) & $8-15$ Years & $1(6.25)$ & $15(93.75)$ & \\
\hline \multirow[t]{2}{*}{ T-cell } & $\mathrm{N}($ Row \%) & Negative & $0(0)$ & $45(100)$ & 0.006 \\
\hline & $\mathrm{N}($ Row \%) & Positive & $1(16.67)$ & $5(83.33)$ & \\
\hline \multirow[t]{2}{*}{ B-cell } & N (Row \%) & Negative & $1(16.67)$ & $5(83.33)$ & 0.006 \\
\hline & $\mathrm{N}($ Row \%) & Positive & $0(0)$ & $45(100)$ & \\
\hline \multirow[t]{2}{*}{ WBC } & $\mathrm{N}($ Row \%) & $<=30000$ & $0(0)$ & $40(100)$ & 0.054 \\
\hline & $\mathrm{N}($ Row \%) & $>30000$ & $1(9.09)$ & $10(90.91)$ & \\
\hline \multirow[t]{2}{*}{ TEL-AML1 } & $\mathrm{N}($ Row \%) & Negative & $1(2.17)$ & $45(97.83)$ & 0.739 \\
\hline & $\mathrm{N}($ Row \%) & Positive & $0(0)$ & $5(100)$ & \\
\hline
\end{tabular}

* The p-value is calculated by chi-square test 
Low Frequency of ETV6-RUNX1 (t 12; 21) in Saudi Arabian Pediatric Acute Lymphoblastic Leukemia Patients

pediatric Acute Lymphoblastic Leukemia (ALL) patients between the ages of 2 to 15 years. Study was approved by King Abdullah International Medical Research Centre (KAIMRC), National Guard Health Affairs, Riyadh, Saudi Arabia.

Along with other laboratory parameters for diagnosis and risk stratification, patients were tested for ETV6RUNX1 using interphase fluorescent in situ hybridization (FISH) as a part of routine laboratory findings.

\section{Interphase fluorescent in situ hybridization (FISH)}

Selection Of Material: Vysis ETV6/RUNX1 DF FISH Probe Kit (Abbot Laboratories, Illinois, USA) was used to detect ETV6/RUNX1 fusion oncogene resulting from $\mathrm{t}(12 ; 21)(\mathrm{p} 13 ; \mathrm{q} 22)$. FISH procedures were carried out according to manufacturer's instructions.

Pre-hybridization, Hybridization and Posthybridization: WBCs were washed with $1 \mathrm{X}$ PBS. Cells were fixed in methanol/acetic acid, dropped on slides, and air dried. The slides were pretreated with " $0.01 \%$ pepsin $+0.02 \mathrm{M} \mathrm{HCl}^{\prime}$ at $37^{\circ} \mathrm{C}$ for $10 \mathrm{~min}$. The cells and probes were denatured on a heating plate together at $78^{\circ} \mathrm{C}$ for $10 \mathrm{~min}$. Hybridization was performed overnight at $37^{\circ} \mathrm{C}$. Posthybridization washing was done in $23 \mathrm{SSC}$ containing $50 \%$ formamide for $7 \mathrm{~min}$ at $42^{\circ} \mathrm{C}$ followed by two washes in $23 \mathrm{SSC}\left(42^{\circ} \mathrm{C}\right.$ for $\left.7 \mathrm{~min}\right)$. The slides were covered by Vectashield (Vector Laboratories, Burlingame, CA) containing $0.5 \mathrm{~g} / \mathrm{ml}$ DAPI.

FISH Analysis: Slides prepared by FISH were analyzed using CytoVision 7.0 system (Applied Imaging, Biosciences Centre, Newcastle, UK).

\section{Treatment protocol \& Clinically Follow-up}

CCG1991 protocol was used for standard risk patients while CCG1961 protocol was used for high risk patients. Number of blasts at day 14 and day 29 of the treatment were also calculated as a part of routine clinical follow-up.

\section{Response criteria}

Complete remission (CR or M1) was defined as: Normal bone marrow (with $<5 \%$ blasts and $>25 \%$ cellularity), neutrophil counts $>1.5 \times 109 / 1$, platelet count $>100 \times 109 / 1$, and all extramedullary disease resolved. Anything less than $\mathrm{CR}$ was considered as incomplete remission (M2 or M3).

\section{Statistical analysis}

The association demographic data, clinical and laboratory parameters and ETV6/RUNX1 status was statistically studied using was performed using SAS version 9.2 (SAS Institute, Inc., Cary, NC). Comparison between ETV6-RUNX1 positive and negative groups done using chi-square test or Fisher's exact test.

\section{Results}

Out of 54 patients, 33 were male and 21 were females (ration1.57:1). B- and T-cell lineage was found in 47 (87\%) and 7 (13\%) patients respectively. Overall, B-cell lineage and WBC count less than 30,000 were significantly associated with complete remission (M1) at day 14 and day 29 (Tables $1 \& 2$ ).

Only $5(9.3 \%)$ patients with ETV6-RUNX1 positive while 49(80.7\%) were ETV6-RUNX1 negative. Mean age of ETV6-RUNX1 positive and ETV6-RUNX1 negative patients was $5.90 \pm 0.495$ and $3 \pm 0.316$, respectively $(<0.001)$. Moreover, $80 \%$ (4/5) of ETV6-RUNX1 positive patients were in 3-7 year age group while $46.94 \%$ (23/49) ETV6-RUNX1 negative patients in this age group. Furthermore, though $36.73 \%$ of ETV6-RUNX1 negative patients were in 8-15 years age group, no ETV6-RUNX1 positive patients were in this age group (Table 3, Figure 1).

Table 3. Demographics and Clinical Characteristics of ETV6-RUNX1 Positive and ETV6-RUNX1 Negative Pediatric Acute Lymphoblastic Leukemia Patients

\begin{tabular}{|c|c|c|c|}
\hline \multirow[t]{2}{*}{ Parameters } & \multicolumn{2}{|c|}{ ETV6-RUNX1 } & \multirow[t]{2}{*}{ P-value* } \\
\hline & Negative $(n=49)$ & Positive $(n=5)$ & \\
\hline \multicolumn{4}{|l|}{ Gender } \\
\hline Female & $19(38.78)$ & $2(40)$ & 0.957 \\
\hline Male & $30(61.22)$ & $3(60)$ & \\
\hline \multicolumn{4}{|l|}{ Age } \\
\hline Mean \pm SEM & $5.90 \pm 0.495$ & $3 \pm 0.316$ & $<0.001$ \\
\hline Median & 5 & 3 & 0.088 \\
\hline Range & $1-13$ & $2-4$ & \\
\hline$<=2$ Years & $8(16.33)$ & $1(20)$ & 0.239 \\
\hline 3 - 7 Years & $23(46.94)$ & $4(80)$ & \\
\hline 8 - 15 Years & $18(36.73)$ & $0(0)$ & \\
\hline \multicolumn{4}{|l|}{ T-cell } \\
\hline Negative & $42(85.71)$ & $5(100)$ & 0.365 \\
\hline Positive & $7(14.29)$ & $0(0)$ & \\
\hline \multicolumn{4}{|l|}{ B-cell } \\
\hline Negative & $7(14.29)$ & $0(0)$ & 0.365 \\
\hline Positive & $42(85.71)$ & $5(100)$ & \\
\hline \multicolumn{4}{|l|}{ WBC (X103) } \\
\hline Mean \pm SEM & $28.61 \pm 8.64$ & $10.68 \pm 5.12$ & 0.083 \\
\hline Median & 9.40 & 6.40 & 0.63 \\
\hline Range & $0-400$ & $3-30$ & \\
\hline$<=30$ & $38(77.55)$ & $4(80)$ & 0.900 \\
\hline$>30$ & $11(22.45)$ & $1(20)$ & \\
\hline \multicolumn{4}{|l|}{ Response @ 14} \\
\hline Poor Response & $4(9.09)$ & $0(0)$ & 0.482 \\
\hline Good Response & $40(90.91)$ & $5(100)$ & \\
\hline \multicolumn{4}{|l|}{ Response@28 } \\
\hline Poor Response & $1(2.17)$ & $0(0)$ & 0.739 \\
\hline Good Response & $45(97.83)$ & $5(100)$ & \\
\hline
\end{tabular}

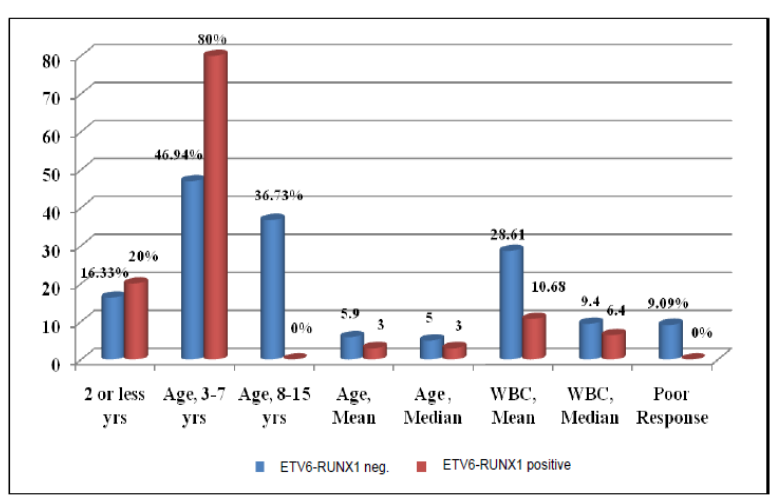

Figure 1. Comparison of Clinical Parameters of ETV6-RUNX1 positive and ETV6-RUNX1 Negative Pediatric Acute Lymphoblastic Leukemia Patients from Saudi Arabia 
All ETV6-RUNX1 patients (100\%) were of B-cell lineage as compared to $85.71 \%$ (42/49) of ETV6-RUNX1 negative patients $(\mathrm{p}=$ ?). Similarly, none of the ETV6RUNX1 positive patients was T-cell lineage as compared to $14.29 \%$ T-cell lineage ETV6-RUNX1 negative patients. Similarly, none of ETV6-RUNX1 positive patients had $\geq 5 \%$ blasts (no remission) at Day 14 as compared to $9 \%$ patients from ETV6-RUNX1 negative group (Table 3, Figure 1).

\section{Discussion}

Our study shows a low representation of ETV6RUNX1 fusion oncogenes among pediatric ALL patients from King Abdulaziz Medical City, National Guard Health Affairs, Riyadh, Saudi Arabia. Most of ETV6-RUNX1 positive (80\%) patients belonged to 3-7 years of age group and allETV6-RUNX1 positive showed early remission (day 14) as compared to 9\% of ETV6-RUNX1 negative patients not showing day 14 remission.

Frequency of ETV6-RUNX1 in this study is in accordance with previous study from middle-east region reporting $14.7 \%$ ETV6-RUNX1 frequency in pediatric ALL patients (Al-Mulla et al., 2014) although it is much lower than the 20-33\% frequency in Europe, US, Japan and Australia (Shurtleff et al., 1995; Harbott et al., 1997; Kobayashi et al., 1997; Amor et al., 1998).

TEL-AML1 frequencies vary greatly in different countries of South East Asia and Southern Asia. A recent study from Pakistani reported the frequency of ETV6RUNX1 in pediatric ALL patients to be $10.2 \%$ (Iqbal, 2014/10). ETV6-RUNX1 frequency has been found to be $17.1 \%$ in Korean pediatric ALL population (Chung et al., 2010), Taiwan 17\% (Liang et al., 1996) and Malaysia 19\% (Gill et al., 2005). In Egypt, ETV6-RUNX1 positivity among pediatric ALL has been reported to be $11.6 \%$ (Shaker et al., 2001). Although most of the studies reported higher ETV6-RUNX1 frequencies in Japan, one study from Hiroshima Japan reported it to be $10 \%$ (Eguchi-Ishimae et al., 1998). Contrary to other European countries, 2\% ETV6-RUNX1 frequency has been reported in Spanish pediatric ALL patients (Garcia-Sanz et al., 1999).All of these studies indicate great ethnic and geographical variations in frequency of this prognostically important genetic abnormality specifically and genetics of pediatric ALL generally, which can have a significant bearing on global pediatric ALL management strategies (Wesołowska-Andersen et al., 2015).

In conclusion, like most of the other developing countries of the region, Saudi Arabia pediatric ALL patients have lower frequencies of ETV6-RUNX1 fusion oncogene than the developed countries like US, Europe, Japan and Canada. Further multicenter studies are required to find out frequencies of other prognostically significant genetic abnormalities in Saudi pediatric ALL patients in order to better plan and manage this highly curable disease in the kingdom.

\section{References}

Al-Ahmadi K, Al-Zahrani A (2013). Spatial autocorrelation of cancer incidence in Saudi Arabia. Int J Environ Res Public Health, 16, 7207-28.

Al-Mulla NA, Chandra P, Khattab M, et al (2014). Childhood acute lymphoblastic leukemia in the Middle East and neighboring countries: a prospective multi-institutional international collaborative study (CALLME1) by the Middle East Childhood Cancer Alliance (MECCA). Pediatr Blood Cancer, 61, 1403-10.

Al-Mutlaq HM, Bawazir AA, Jradi H, et al (2015). A. Patterns of childhood cancer incidence in Saudi Arabia (1999-2008). Asian Pac J Cancer Prev, 16, 431-5.

Alghamdi IG, Hussain II, Alghamdi MS, et al (2014). The incidence of leukemia in Saudi Arabia. Descriptive epidemiological analysis of data from the Saudi Cancer Registry 2001-2008. Saudi Med J, 35, 674-83.

Amor DJ, Algar EM, Slater HR, et al (1998). High frequency of $\mathrm{t}(12 ; 21)$ in childhood acute lymphoblastic leukemia detected by RT-PCR. Pathol, 30, 381-5.

Awan T, Iqbal Z, Aleem A, et al (2012). Five most common prognostically important fusion oncogenes are detected in the majority of Pakistani pediatric acute lymphoblastic leukemia patients and are strongly associated with disease biology and treatment outcome. Asian Pac J Cancer Prev, 13, 5469-75.

Bhojwani D, Yang JJ, Pui CH (2015). Biology of childhood acute lymphoblastic leukemia. Pediatr Clin North Am, 62, 47-60.

Ceppi F, Cazzaniga G, Colombini A, et al (2015). Risk factors for relapse in childhood acute lymphoblastic leukemia: prediction and prevention. Expert Rev Hematol, 8, 57-70.

Chung HY, Kim KH, Jun KR, et al (2010). Prognostic Significance of TEL/AML1 Rearrangement and Its Additional Genetic Changes in Korean Childhood Precursor B-Acute Lymphoblastic Leukemia. Korean J Lab Med, 30, 1-8.

Cooper SL, Brown PA (2015). Treatment of pediatric acute lymphoblastic leukemia. Pediatr Clin North Am, 62, 61-73.

Eguchi-Ishimae M, Eguchi M, Tanaka K, et al (1998). Fluorescence in situ hybridization analysis of $12 ; 21$ translocation in Japanese childhood acute lymphoblastic leukaemia. Jpn J Cancer Res, 89, 783-88.

Faiz M, Qazi JI (2010). t(12:21) Is underrepresented in childhood B-lineage acute lymphoblastic leukemia in Punjab, Pakistan. J Pediatr Hematol Oncol, 32, 249-51.

Garcia-Sanz R, Alaejos I, Orfao A, et al (1999). Low frequency of the TEL/AML1 fusion gene in acute lymphoblastic leukemia in Spain. Br J Haematol, 107, 667-9.

Gill HK, Keoh TS, Dhaliwal JS, et al (2005). TEL-AML1 frequency in multi ethnic Malaysian pediatric acute lymphoblastic leukemia. Cancer Genet Cytogenet, 156, 129-33.

Harbott J, Viehmann S, Borkhardt A, et al (1997). Incidence of TEL/AML1 fusion gene analyzed consecutively in children with acute lymphoblastic leukemia in relapse. Blood, $\mathbf{9 0}$, 4933-7.

Inaba H, Greaves M, Mullighan CG (2013). Acute lymphoblastic leukaemia. Lancet, 381, 1943-55.

Iqbal Z (2014). Molecular genetic studies on 167 pediatric ALL patients from different areas of Pakistan confirm a low frequency of the favorable prognosis fusion oncogene TEL-AML1 (t 12; 21) in underdeveloped countries of the region. Asian Pac J Cancer Prev, 15, 3541-6.

Iqbal Z, Iqbal M, Akhter T (2007). Frequency of BCR-ABL fusion oncogene in Pakistani childhood acute lymphoid leukemia (ALL) patients reflects ethnic differences in molecular genetics of ALL. J Pediatr Hematol Oncol, 29, 585.

Kobayashi H, Satake N, Kaneko Y (1997). Detection of the Der 
(21) $\mathrm{t}(12 ; 21)$ chromosome forming the TEL-AML1 fusion gene in childhood acute lymphoblastic leukemia. Leuk Lymphoma, 28, 43-50.

Kwong YL, Wong KF (1997). Low frequency of TEL-AML1 in adult acute lymphoblastic leukemia. Cancer Genet Cytoge, 98, 137-8.

Liang DC, Chou TB, Chen JS, et al (1996). High incidence of TEL/AML1 fusion resulting from a cryptic $t(12 ; 21)$ in childhood B-lineage acute lymphoblastic leukemia in Taiwan. Leukemia, 10, 991-3.

Mazloumi SH, Madhumathi DS, Appaji L, et al (2012). Combined study of cytogenetics and fluorescence in situ hybridization (FISH) analysis in childhood acute lymphoblastic leukemia (ALL) in a tertiary cancer centre in South India. Asian Pac J Cancer Prev, 13, 3825-7.

Moorman AV, Enshaei A, Schwab C, et al (2014). A novel integrated cytogenetic and genomic classification refines risk stratification in pediatric acute lymphoblastic leukemia. Blood, 124, 1434-44.

Pui CH, Pei D, Coustan-Smith E, et al (2015). Clinical utility of sequential minimal residual disease measurements in the context of risk-based therapy in childhood acute lymphoblastic leukaemia: a prospective study. Lancet Oncol, 16, 465-74.

Rahman SA, Mohadess Ardabili SM, Aghazadeh A, et al (2006). Investigation of TEL-AML1 and BCR-ABL fusion oncogenes in patients affected by acute Lymphoblastic leukemia using interphase in situ hybridization. J Sc Islamic Rep Iran, 17, 17-5.

Ribera JM, Oriol A (2009). Acute lymphoblastic leukemia in adolescents and young adults. Hematol Oncol Clin North Am, 23, 1033-42.

Saudi Arabian National Guard (2015). In Wikipedia, The Free Encyclopedia. Retrieved 07:30, May 20, 2015, from http://en.wikipedia.org/w/index.php?title=Saudi_Arabian_ National_Guard\&oldid=662239904, May 14 .

Shaker HM, Sidhom IA, El-Attar IA (2001). Frequency and clinical relevance of TEL-AML1 fusion gene in childhood acute lymphoblastic leukemia in Egypt. J Egyptian Natl Cancer Inst, 13, 9-18.

Shurtleff SA, Buijs A, Behm FG, et al (1995). TEL/AML1 fusion resulting from a cryptic $t(12 ; 21)$ is the most common genetic lesion in pediatric ALL and defines a subgroup of patients with an excellent prognosis. Leukemia, 9, 1985-9.

Tsang KS, Li CK, Chik KW, et al (2001). TEL/AML1 rearrangement and the prognostic significance in childhood acute lymphoblastic leukemia in Hong Kong. Am J Hematol, 68, 91-8.

Wesołowska-Andersen A, Borst L, Dalgaard MD, et al (2015). Genomic profiling of thousands of candidate polymorphisms predicts risk of relapse in 778 Danish and German childhood acute lymphoblastic leukemia patients. Leukemia, 29, 297 303. 